\title{
Long-Term Outcomes of Restorative Neurostimulation in Patients With Refractory Chronic Low Back Pain Secondary to Multifidus Dysfunction: Two-Year Results of the ReActiv8-B Pivotal Trial
}

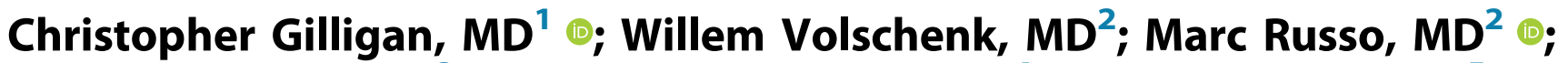
Matthew Green, MD $^{3}$; Christopher Gilmore, MD $^{4}{ }^{\circ}$; Vivek Mehta, MD $^{5}$; Kristiaan Deckers, $\mathrm{MD}^{6}$; Kris De Smedt, $\mathrm{MD}^{7}$; Usman Latif, MD, MBA ${ }^{8}{ }^{\circ}$; Peter Georgius, MD ${ }^{9}$; Jonathan Gentile, MD ${ }^{10}$; Bruce Mitchell, MD $^{11}{ }^{\circ}$; Meredith Langhorst, $\mathrm{MD}^{12}{ }^{\circ}$; Frank Huygen, $\mathrm{MD}, \mathrm{PhD}^{13}$; Ganesan Baranidharan, $\mathrm{MD}^{14}$; Vikas Patel, $\mathrm{MD}^{15}$; Eugene Mironer, $\mathrm{MD}^{16}$; Edgar Ross, $\mathrm{MD}^{1}$; Alexios Carayannopoulos, DO, $\mathrm{MPH}^{17}$; Salim Hayek, MD, PhD ${ }^{18}$; Ashish Gulve, MD ${ }^{19}{ }^{\circ}$; Jean-Pierre Van Buyten, MD, PhD $^{20}$; Antoine Tohmeh, MD $^{21}$; Jeffrey Fischgrund, $\mathrm{MD}^{22}$; Shivanand Lad, $\mathrm{MD}, \mathrm{PhD}^{23}$;

Farshad Ahadian, MD ${ }^{24}{ }^{\circ}$; Timothy Deer, MD ${ }^{25}$; William Klemme, MD $^{26}{ }^{\circ}$; Richard Rauck, MD $^{27}$; James Rathmell, MD $^{1}{ }^{\circ}$; Greg Maislin, MS $^{28}{ }^{\circ}$; Jan Pieter Heemels, MSc ${ }^{29}$; Sam Eldabe, MD ${ }^{19}$; On Behalf of the ReActiv8-B Investigators

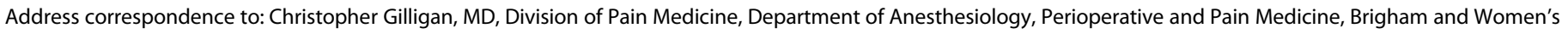
Hospital, 850 Boylston St, Suite 320, Chestnut Hill, MA 02467, USA. Email: cgilligan@bwh.harvard.edu

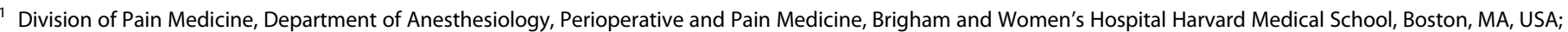

Hunter Pain Specialists, Newcastle, Australia;

3 Pain Medicine of SA, Adelaide, Australia;

${ }^{4}$ Center for Clinical Research, Carolinas Pain Institute, Winston-Salem, NC, USA;

5 Barts Neuromodulation Centre, St. Bartholomew's Hospital, London, UK;

6 Department of Physical Medicine and Rehabilitation, GZA - Sint Augustinus Hospital, Wilrijk, Belgium;

7 Department of Neurosurgery, GZA - Sint Augustinus Hospital, Wilrijk, Belgium;

8 Department of Anesthesiology, University of Kansas School of Medicine, Kansas City, KS, USA;

9 Sunshine Coast Clinical Research, Noosa Heads, Australia;

10 Indiana Spine Group, Indianapolis, IN, USA;

11 Metro Pain Group, Melbourne, Australia;

12 Ortholndy, Indianapolis, IN, USA;

13 Department of Anaesthesiology, Erasmus Medical Center, Rotterdam, The Netherlands;

14 Leeds Pain and Neuromodulation Centre, Leeds Teaching Hospitals NHS Trust, Leeds, UK:

15 Department of Orthopedic Surgery, University of Colorado, Denver, CO, USA;

16 Carolinas Center for the Advanced Management of Pain, Spartanburg, NC, USA;

17 Department of Physical Medicine and Rehabilitation, Rhode Island Hospital, Brown University Medical School, Providence, RI, USA;

18 Division of Pain Medicine, University Hospitals, Cleveland Medical Center, Cleveland, OH, USA;

19 Department of Pain Medicine, The James Cook University Hospital, Middlesbrough, UK;

20 AZ Nikolaas Multidisciplinary Pain Center, Sint Niklaas, Belgium;

21 Multicare Neuroscience Institute, Spokane, WA, USA;

22 Department of Orthopedic Surgery, Oakland University, Beaumont Hospital, Royal Oak, MI, USA;

23 Department of Neurosurgery, Duke University Medical Center, Durham, NC, USA;

24 Center for Pain Medicine, University of California, San Diego, CA, USA;

25 The Spine and Nerve Center of the Virginias, Charleston, WV, USA;
} 


\section{ABSTRACT}

Background: Impaired neuromuscular control and degeneration of the multifidus muscle have been linked to the development of refractory chronic low back pain (CLBP). An implantable restorative-neurostimulator system can override the underlying multifidus inhibition by eliciting episodic, isolated contractions. The ReActiv8-B randomized, active-sham-controlled trial provided effectiveness and safety evidence for this system, and all participants received therapeutic stimulation from four months onward.

Objective: This study aimed to evaluate the two-year effectiveness of this restorative neurostimulator in patients with disabling CLBP secondary to multifidus muscle dysfunction and no indications for spine surgery.

Materials and Methods: Open-label follow-up of 204 participants implanted with a restorative neurostimulation system (ReActiv8, Mainstay Medical, Dublin, Ireland) was performed. Pain intensity (visual analog scale [VAS]), disability (Oswestry disability index [ODI]), quality-of-life (EQ-5D-5L), and opioid intake were assessed at baseline, six months, one year, and two years after activation.

Results: At two years $(n=156)$, the proportion of participants with $\geq 50 \%$ CLBP relief was $71 \%$, and $65 \%$ reported CLBP resolution (VAS $\leq 2.5 \mathrm{~cm}) ; 61 \%$ had a reduction in ODI of $\geq 20$ points, $76 \%$ had improvements of $\geq 50 \%$ in VAS and/or $\geq 20$ points in ODI, and $56 \%$ had these substantial improvements in both VAS and ODI. A total of $87 \%$ of participants had continued device use during the second year for a median of $43 \%$ of the maximum duration, and $60 \%$ (34 of 57) had voluntarily discontinued (39\%) or reduced $(21 \%)$ opioid intake.

Conclusions: At two years, $76 \%$ of participants experienced substantial, clinically meaningful improvements in pain, disability, or both. These results provide evidence of long-term effectiveness and durability of restorative neurostimulation in patients with disabling CLBP, secondary to multifidus muscle dysfunction.

Clinical Trial Registration: The study is registered on clinicaltrials.gov with identifier NCT02577354.

Keywords: Chronic low back pain, durability, functional segmental stability, multifidus muscle, restorative neurostimulation

Conflicts of Interest: Mainstay Medical ("Mainstay") funded this pivotal regulatory trial and compensated all investigators and committee members either directly (personal fees) or indirectly (payments to institution). Travel expenses related to investigator meetings and training were reimbursed only with prior authorization.

Disclosures outside the submitted work: $C$. Gilligan reports payment of part of his salary to his department and stock-options received from Mainstay, personal fees from Medtronic, Saluda, Abbott, Persica, Eli Lilly, lliad, research funded by Sollis, and expert witness testimony fees; W. Vollschenk reports personal fees from Mainstay; M. Russo reports personal fees from Mainstay; C. Gilmore reports personal fees and other from SPR, and personal fees from Nevro, Nalu, Biotronik, Boston Scientific, and Saluda; V. Mehta reports grants from Mainstay and Abbott, grants and personal fees from Boston Scientific and Medtronic; K. De Smedt reports personal fees from Mainstay; U. Latif reports personal fees from Medtronic; P. Georgius reports personal fees from Boston Scientific, Abbott and Spectrum; J. Gentile reports personal fees from Mainstay; B. Mitchell reports personal fees from Mainstay; M. Langhorst reports personal fees from Mainstay and Vivex; F. Huygen reports grants and personal fees from Abbott and Saluda, and nonfinancial support from Boston Scientific; G. Baranidharan reports a grant from Mainstay, grants and personal fees from Nevro, Abbott, Boston Scientific, and personal fees from Nalu and Stryker; V. Patel reports personal fees from Mainstay, grants from Orthofix, Pfizer, Premia Spine, Medicrea, Globus, Aesculap, and 3-Spine; A. Gulve reports personal fees from Medtronic and Boston Scientific, grants and personal fees from Nevro and Abbott; J.P. Van Buyten reports personal fees from Mainstay, and grants and personal fees from Medtronic, Nevro, Boston Scientific and Abbott; A. Tohmeh reports stock ownership and personal fees with two spine companies; J. Fishgrund reports personal fees from Stryker, Relievant, FzioMed, BioVentus and Asahi Kasei; F. Ahadian reports a grant from Mainstay; T. Deer reports grants, personal fees, and other from Abbott, Saluda and SPR, grants and personal fees from Boston Scientific, personal fees and other from SpineThera, Nalu, Cornerloc and Ethos, personal fees from Stimgenics, Flowonix and SI Bone, and a patent pending with Abbott; J. Rathmell reports personal fees from the American Board of Anesthesiology, and personal fees from the American Society of Anesthesiology; G. Maislin reports personal fees from Mainstay. J.P. Heemels reports personal fees and equity interests with Mainstay; S. Eldabe reports personal fees and non-financial support from Mainstay, grants and personal fees from Medtronic, and other from Abbott.

The remaining authors have no conflicts of interest to disclose outside of the submitted work.

26 Uniformed Services University of the Health Sciences, Bethesda, MD, USA;

${ }^{27}$ Carolinas Pain Institute, Wake Forest University, Winston-Salem, NC, USA;

${ }^{28}$ Biomedical Statistical Consulting, Wynnewood, PA, USA; and

29 Department of Scientific Affairs, Mainstay Medical, Dublin, Ireland

For more information on author guidelines, an explanation of our peer review process, and conflict of interest informed consent policies, please see the journal's Guide for Authors.

Source(s) of financial support: This study was funded by Mainstay Medical. 


\section{INTRODUCTION}

Most cases of acute low back pain resolve spontaneously without treatment, but for chronic low back pain (CLBP), the prognosis is not favorable. ${ }^{1}$ Patients with CLBP often endure impaired quality of life, depression, anxiety, and sleep disturbance. ${ }^{2,3}$ Most CLBP patients suffer from mechanical/musculoskeletal pain that is predominantly nociceptive in nature and have no indication for spine surgery. ${ }^{4-7}$

The multifidus muscles are the most important stabilizers of the lumbar spine and play a crucial role in providing segmental stability in response to changes in posture and protection against sudden perturbations..$^{8-10}$ Mechanical CLBP is often associated with impaired neuromuscular control and degeneration of the lumbar multifidus muscles. ${ }^{9,11-13}$ Persistent back pain-induced inhibition and disruption of proprioceptive signaling have also been linked to long-term motor cortex reorganization. ${ }^{14}$ Results of motor control exercise programs specifically targeting the multifidus muscle are mixed. ${ }^{15,16}$ The isolated muscle contractions required to reverse impaired neuromuscular control are difficult to achieve voluntarily, especially in the presence of underlying inhibition and degeneration of the multifidus muscle. ${ }^{17,18}$ To overcome these limitations to rehabilitation, a restorative neurostimulation system (ReActiv8, Mainstay Medical, Dublin, Ireland) was developed to electrically stimulate the medial branch of the $L 2$ dorsal ramus nerve to elicit isolated multifidus muscle activation. ${ }^{19,20}$

A recent double-blind, randomized, sham-controlled pivotal trial provided safety and effectiveness evidence for premarket approval from the United States Food and Drug Administration (FDA) in 2020. ${ }^{21}$

The objective of the prospective, observational analyses reported here was to evaluate the two-year effectiveness of this restorative neurostimulator in patients with disabling CLBP secondary to multifidus muscle dysfunction and no indications for spine surgery.

\section{MATERIALS AND METHODS}

Data for this secondary analysis were obtained from the cohort of 204 patients enrolled at 26 multidisciplinary centers in the United States, Australia, and Europe in the randomized, sham-controlled, double-blind pivotal trial. All patients were receiving therapeutic stimulation from four months onward. Details regarding patient eligibility, study design, implant procedure, and medium-term results through one year have been previously published. ${ }^{21}$

\section{Patients}

Study participants were adults with a diagnosis of disabling mechanical CLBP (ie, a seven-day recall of average LBP of $\geq 6.0$ and $\leq 9.0 \mathrm{~cm}$ on the $10-\mathrm{cm}$ visual analog scale [VAS] and Oswestry disability index [ODI] of $\geq 21$ and $\leq 60$ points on a scale from 0 to 100). Mechanical CLBP was defined as low back pain without significant radicular symptoms. Participants had low back pain on at least half of the days in the previous year, were nonresponsive to a minimum of 90 days of nonsurgical medical management including medication and physical therapy, and had a positive prone instability test result (provocative pain test using posterioranterior pressure on individual lumbar vertebrae that improves with activation of the posterior lumbar musculature) consistent with impaired neuromuscular control of the multifidus muscle and consequent lumbar segmental instability. ${ }^{22}$ Full eligibility criteria are provided in the Supplementary Data.

\section{Trial Design and Oversight}

The conduct of the trial complied with the FDA regulations, ISO 14155, International Conference on Harmonization, and the Declaration of Helsinki. Local institutional review board or ethics committee approval was obtained at each site, and all participants provided written informed consent. Results are reported in accordance with the Consolidated Standards of Reporting Trials (CONSORT) guidelines. ${ }^{23}$ The study is registered on clinicaltrials.gov with identifier NCT02577354.

\section{Procedures}

All participants received the implanted restorative neurostimulation system (Fig. 1).

During the open-label phase of the trial, all devices were programmed to deliver therapeutic stimulation at a frequency of 20 $\mathrm{Hz}$, a pulse width of $214 \mu \mathrm{sec}$, and participant-specific pulse amplitudes and electrode configurations to elicit tonic multifidus contractions for 10 seconds twice per minute. All participants were instructed and trained to deliver two 30-minute stimulation sessions per day while prone or lying on their side using their wireless activator.

\section{Outcomes}

Prespecified outcome measures included the seven-day recall of average low back pain on the 10-cm VAS, ${ }^{24}$ ODI, ${ }^{25}$ EQ-5D index (EuroQol quality-of-life survey [EQ-5D-5L]), ${ }^{26}$ percentage of pain relief (PPR), subject global impression of change (SGIC), ${ }^{27}$ LBP resolution which we defined as VAS $\leq 2.5 \mathrm{~cm}$, treatment satisfaction questionnaire (TSQ), clinical global impression of change (CGI), ${ }^{28}$ and medication usage. These outcomes were assessed and compared with baseline at six months and one and two years, and annual follow-ups are scheduled for a total of five years.

Ongoing safety reporting included serious device- or procedurerelated adverse events (AEs) that were actively solicited and documented at each visit and reported and coded according to the Medical Dictionary for Regulatory Activities, version 19.1. The Clinical Events Committee (CEC) adjudicated all AEs.

\section{Data Analysis}

Descriptive statistics including mean and standard deviation or standard error of the mean, $95 \%$ confidence intervals (Cls), median, first and third quartiles (Q1 and Q3) were used to summarize continuous variables. Binary outcomes were represented as counts and proportions.

To reduce potential bias caused by incomplete follow-up, imputation for missing data was stratified based on the reason for missingness. Baseline observation carried forward, or "failure" for binary outcomes, was used for participants withdrawn for reported lack of efficacy at any time or for permanent explant after infection. For those withdrawn for other reasons (ie, precautionary device removal for magnetic resonance imaging [MRI], resolution of pain, a relocation, or otherwise lost to follow-up) or random missed visits, the mixed-effects model repeated measures (MMRM) approach was used to provide implicit imputations of missing data for continuous outcomes. ${ }^{29}$ To evaluate mean changes from baseline, $95 \% \mathrm{Cls}$ and adjusted paired $t$-tests derived from MMRM 


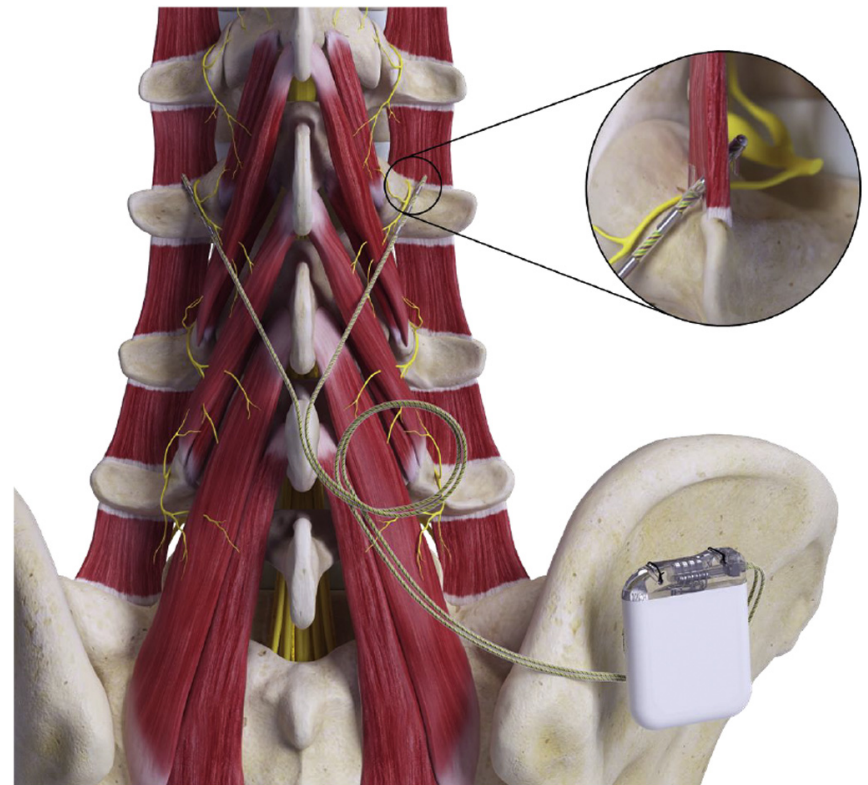

Figure 1. Implantation procedure and materials. Stimulation leads were placed bilaterally near the L2 medial branch of the dorsal ramus nerve as it crosses the $\mathrm{L} 3$ transverse process and distally fixated to the L2/3 intertransversarii using flexible tines. The proximal sections were tunneled subcutaneously to the surgically created pocket in the gluteal or lower lumbar region where they were connected directly to the implantable pulse generator.

contrasts were used. Two-sided $p$ values less than 0.05 were considered statistically significant.

To estimate the proportion of patients achieving "success" for the defined binary outcome variables, multiple imputation (MI) was used for overall estimates of success by visit with associated $95 \%$ confidence limits. $^{30,31}$

Analyses were performed using SAS version 9.3 (SAS Institute Inc, Cary, NC).

\section{RESULTS}

\section{Study Population}

The demographic and baseline characteristics of the 204 participants are summarized in Table 1. Participants had a mean age of $47 \pm 9$ years, and $54 \%$ were women. The mean duration of CLBP was $14 \pm 11$ years (range from 7 months to 50 years) from the onset of the first occurrence, and the mean percentage of days with LBP in the previous year was $97 \pm 8 \%$. The mean VAS was $7.3 \pm 0.7 \mathrm{~cm}$, the mean ODI was $39 \pm 10$, and the mean EQ-5D-5L index was $0.585 \pm 0.174$. All participants had undergone physical therapy with an average of $31 \pm 52$ sessions. Of all participants, $12 \%$ had undergone medial branch rhizotomy (>1 year before enrollment), 49\% had received spinal injections ( $>30$ days before enrollment), and $37 \%$ were taking opioid analgesics for LBP.

\section{Participant Disposition}

Longitudinal follow-up data were available for 190 of 204 participants (93\%) at six months, 176 of 204 (86\%) at one year, and 156 of 204 (79\%) at two years (Fig. 2).

At the two-year follow-up, ten participants had missed their follow-up visit, and 38 participants had been withdrawn from the
Table 1. Baseline Characteristics of the Study Population at Baseline.

\begin{tabular}{|c|c|}
\hline Characteristic & $\begin{array}{l}\text { Participants } \\
\text { Combined group } \\
(N=204) \\
\text { Mean } \pm \text { SD or } n / N(\%)\end{array}$ \\
\hline Age (y) & $47 \pm 9$ \\
\hline Female sex & $110 / 204(54)$ \\
\hline Body mass index (BMI)* & $28 \pm 4$ \\
\hline $\begin{array}{l}\text { Pain duration from onset of } \\
\text { the first occurrence }(y)\end{array}$ & $14.2 \pm 10.6$ \\
\hline $\begin{array}{l}\text { Percent of days with low back } \\
\text { pain in the past year }\end{array}$ & $97 \pm 8$ \\
\hline Leg pain associated with back pain & $53 / 204(26)$ \\
\hline Previous medial branch rhizotomy & $25 / 204(12)$ \\
\hline Months from most recent rhizotomy & $44.4 \pm 74.7$ \\
\hline Previous injection procedure & 99/204 (49) \\
\hline $\begin{array}{l}\text { Number of previous physical } \\
\text { therapy sessions }\end{array}$ & $31 \pm 52$ \\
\hline \multicolumn{2}{|l|}{ Medications for low back pain } \\
\hline $\begin{array}{l}\text { At least one medication for } \\
\text { low back pain }\end{array}$ & 162/204 (79) \\
\hline NSAIDs & $98 / 204(48)$ \\
\hline Opioid-analgesics & $76 / 204(37)$ \\
\hline Simple analgesics & $42 / 204(21)$ \\
\hline Muscle relaxants & $16 / 204(8)$ \\
\hline Anticonvulsants & 18/204 (9) \\
\hline Other $(\leq 5 \%)$ & $24 / 204(12)$ \\
\hline VAS score for low back pain ${ }^{+}$ & $7.3 \pm 0.7$ \\
\hline ODI score & $39 \pm 10$ \\
\hline EQ-5D-5L index ${ }^{\S}$ & $0.585 \pm 0.174$ \\
\hline \multicolumn{2}{|c|}{$\begin{array}{l}\text { *The BMI is the weight in kilograms divided by the square of the height in } \\
\text { meters. } \\
\text { }{ }^{+} \text {Scores on the VAS for average recall low back pain over the past seven } \\
\text { days range from } 0 \text { to } 10 \text {, with higher scores indicating more severe pain. } \\
\text { FScores on the ODI range from } 0 \text { to } 100 \text {, with higher scores indicating } \\
\text { more severe disability. } \\
\text { \$S Scores on the European Quality of Life with five dimensions and five } \\
\text { levels (EQ-5D-5L) index range from - } 0.5 \text { to 1, with higher scores indicating } \\
\text { better quality of life. }\end{array}$} \\
\hline
\end{tabular}

study after permanent system explant (31) or otherwise lost to follow-up (7). One participant in whom the system was explanted for infection was reimplanted after the infection had cleared (Fig. 2).

\section{Two-Year Outcomes}

Completed-Cases Analysis ( $n=156$ )

Key efficacy outcomes progressively improved over time, and changes from baseline were statistically significant and clinically meaningful at all follow-ups ( $p<0.0001$; Figs. 3 and 4, Table 2). ${ }^{32-35}$ By two years, the mean average LBP VAS had improved by $-4.8 \pm$ $0.2 \mathrm{~cm}(95 \% \mathrm{Cl}-5.2$ to $-4.5 ; p<0.0001)$, and $72 \%$ of participants had a $\geq 50 \%$ reduction in VAS, with an average reduction of $85 \%$, $62 \%$ of participants had a $\geq 70 \%$ VAS reduction, and $67 \%$ had resolution of CLBP (VAS $\leq 2.5 \mathrm{~cm}$ ), with an average residual VAS of 0.97 $\mathrm{cm}$. The mean ODI score decreased by $-21.4 \pm 1.3(95 \% \mathrm{Cl}-24.0$ to $-18.7 ; p<0.0001$ ), and $62 \%$ of participants had a $\geq 20$-point ODI reduction, with an average reduction of 32 points. The mean EQ5D-5L index improved by $0.218 \pm 0.017$ ( $95 \% \mathrm{Cl} 0.184$ to 0.253 ; $p<0.0001)$. The proportion of participants with a reduction in LBP VAS of $\geq 50 \%$ and/or ODI of $\geq 20$ points without an increase in 


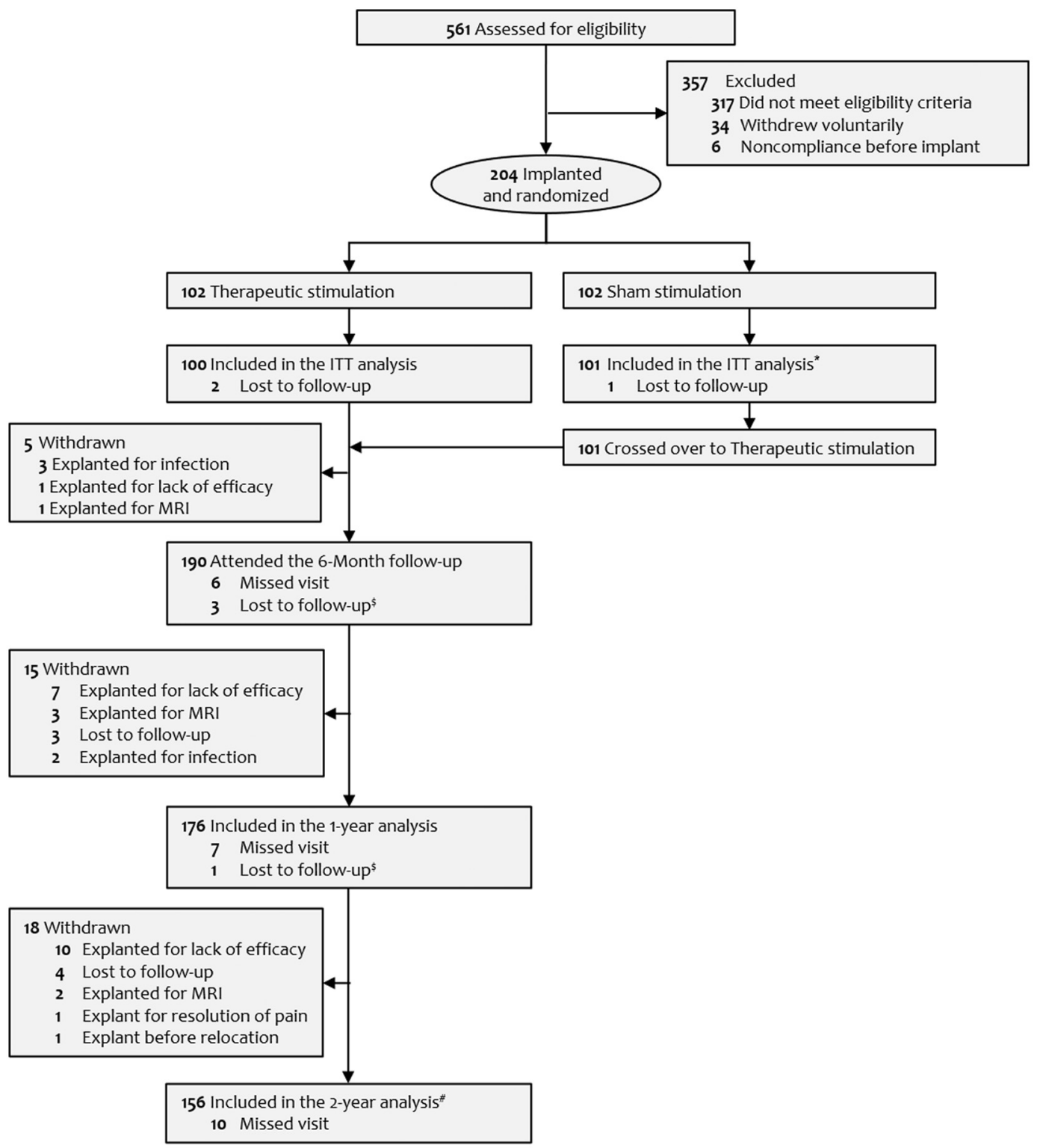

* 4 explanted patients who attended the 120-day visit were counted as non-responders.

* 1 patient did not complete the LBP VAS at this visit.

$\$ 4$ patients lost to follow-up were not officially withdrawn until later in the study

Figure 2. CONSORT flow diagram for participant disposition.

either was $77 \%$. The proportion who exceeded these cut-offs in both VAS and ODI was $57 \%$. Within the cohort of participants with two-year follow-up data, 57 of $156(37 \%)$ were taking opioid analgesics at baseline, 34 of $57(60 \%)$ had voluntarily discontinued (39\%) or reduced (21\%) opioid use, and 1 of $57(2 \%)$ had increased dosage.

Imputed Analysis $(N=204)$

A side-by-side comparison of the completed-cases analysis ( $n=156)$ and the imputed intention-to-treat (ITT) analysis $(N=204)$ is provided in Table 2. Reported outcomes remained statistically significant $(p<0.0001)$ and clinically meaningful at all follow-ups.
Device Use

Over $94 \%$ of participants continued delivering treatment between one and two years. During the 60 days leading to the sixmonth follow-up, the median device use was 88\% (Q1 73\%, Q3 $96 \%$ ) of the maximum duration possible (number of days times the maximum duration of 60 minutes daily); for the 90 days leading to the 12-month follow-up, it was 77\% (Q1 48\%, Q3 90\%); and for the 90 days leading to the 24-month follow-up, it was 42\% (Q1 6.5\%, Q3 75\%) (Fig. 5).

\section{Safety Analysis}

Device- or procedure-related serious AEs (SAEs) are summarized in Table 3 by follow-up interval. Events through the one-year visit 
a

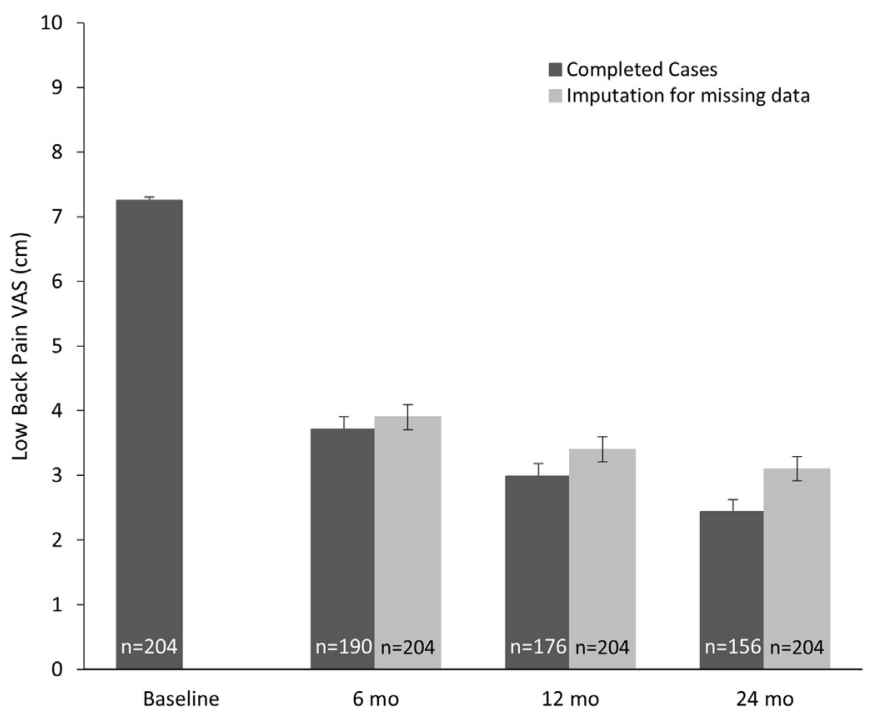

b

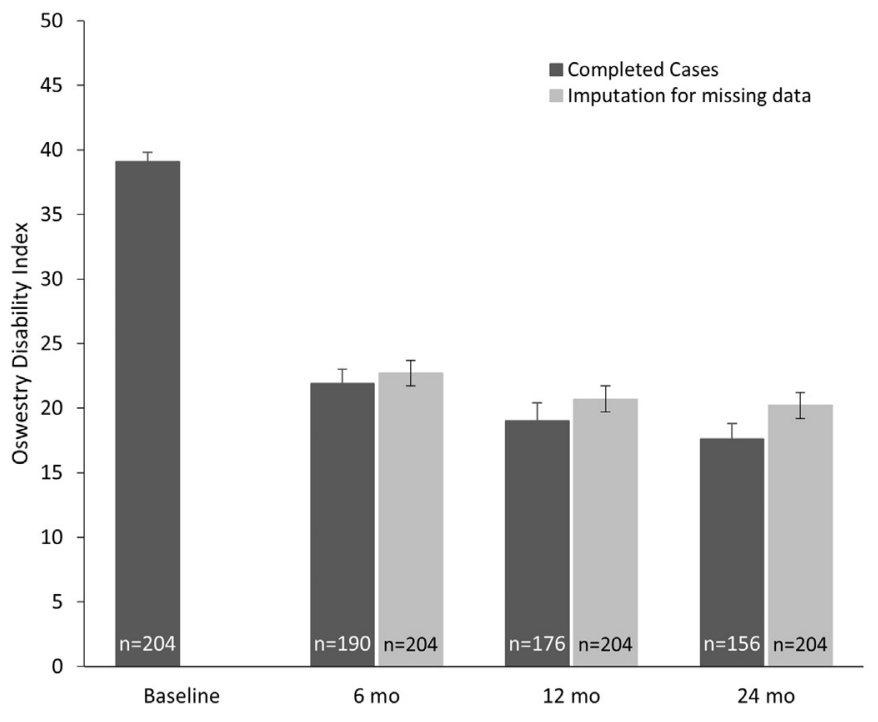

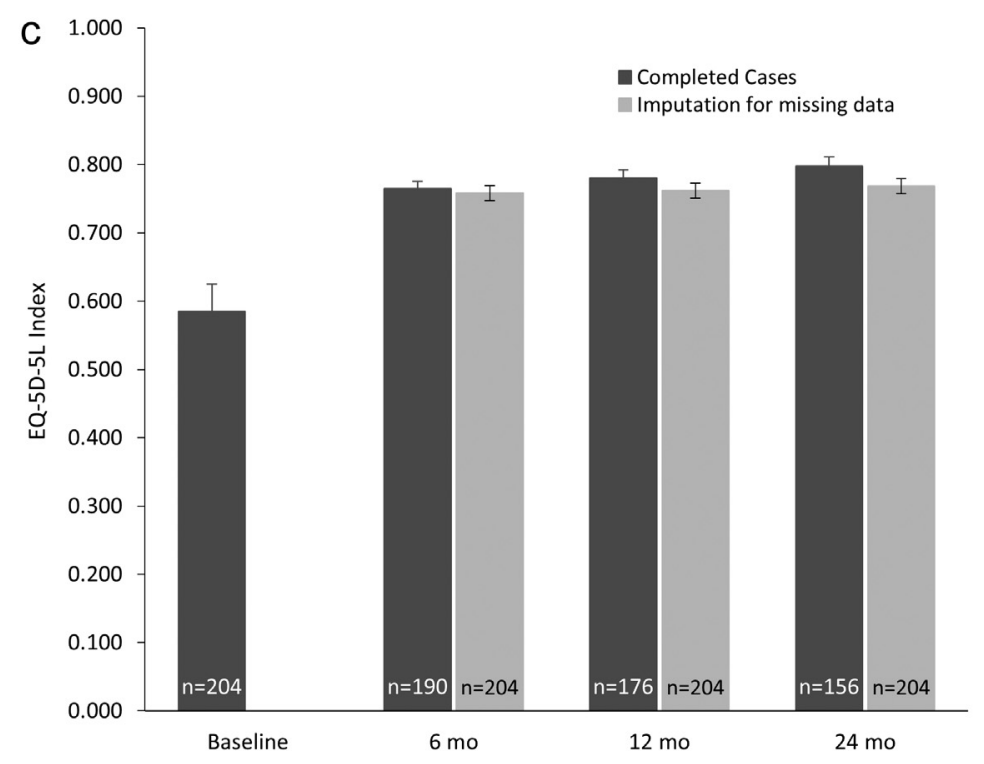

Figure 3. Mean ratings over time for a. low back pain VAS, b. Oswestry disability index, and c. EQ-5D-5L index. All changes from baseline $p<0.0001$. Error bars represent the standard error of the mean.

have been discussed previously. ${ }^{21}$ No additional device- or procedure-related SAEs were reported, and no lead migrations were observed. Overall, 45 of 204 participants (22\%) underwent a total of 47 surgical interventions, during which 32 systems were removed $(16 \%)$, one system was reimplanted $(<1 \%)$, four pulse generators were repositioned (2\%), and ten participants had their leads replaced (5\%). Reasons for system removal were lack of efficacy $(n=18)$, infection ( $n=6)$, safety precaution before MRI scan $(n=6)$, resolution of $\operatorname{LBP}(n=1)$, and relocation to a remote area without device follow-up infrastructure $(n=1)$. Seven unrelated SAEs were reported for seven participants (3\%) during the first year, and six unrelated SAEs were reported for six participants (3\%) during the second year of the follow-up. All 13 events were reviewed by the CEC and adjudicated as unrelated to the device or procedure.

\section{DISCUSSION}

Restorative neurostimulation is indicated for patients with refractory mechanical CLBP secondary to multifidus muscle dysfunction and no pathology seen on MRI that is clearly identified and is likely the cause of the CLBP that is amenable to surgery.

Before enrollment, all participants had failed conventional medical management, which included at least physical therapy and medication for LBP. Most participants had undergone one or more interventional procedures, and over a third were on chronic opioids. Published studies on this condition consistently report that these patients very rarely experience spontaneous, substantial improvements in their pain and disability. ${ }^{1,36-41}$

Longitudinal follow-ups demonstrated a progressive recovery trajectory that is consistent with restoration of multifidus 


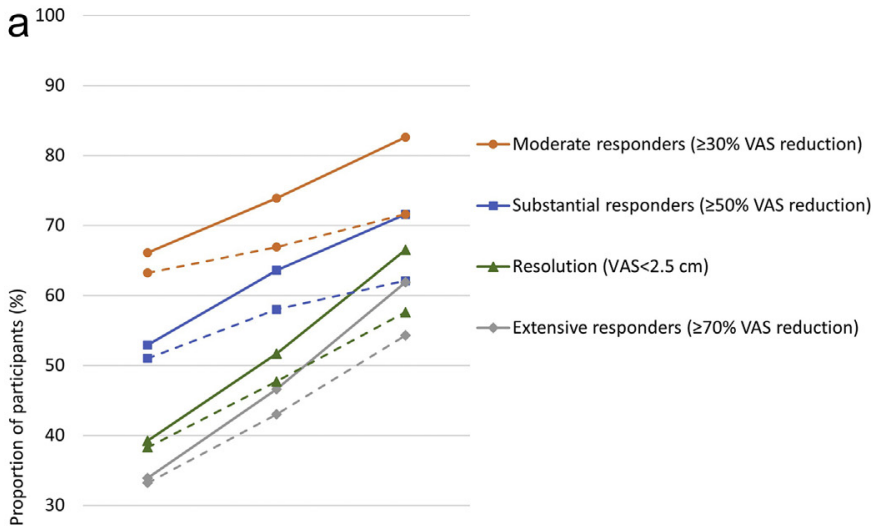

20

10

$$
\begin{array}{ccc}
6 \text { mo } & 12 \text { mo } & 24 \text { mo } \\
(n=190) & (n=176) & (n=156)
\end{array}
$$

$b^{100}$

$$
90
$$

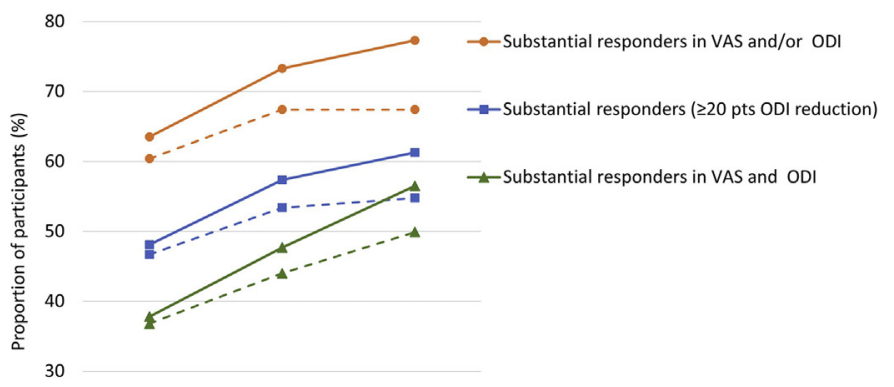

20

10

0

Figure 4. Response rates at common clinical importance thresholds for a. VAS (reduction $\geq 50 \%$ and $70 \%$, and absolute VAS $\leq 2.5 \mathrm{~cm}$ ), and b. ODI ( $\geq 20$ points) and composites of VAS and ODI ( $\geq 50 \%$ and/or 20 points, $\geq 50 \%$ and/or 20 points). Solid lines represent completed cases, and dashed lines represent imputation for missing data $(N=204)$. [Color figure can be viewed at www.neuromodulationjournal.org]

neuromuscular control. At the two-year follow-up, durable and clinically substantial benefits had accrued in all predefined outcome measures $(p<0.0001)$. Although the study did not directly compare restorative neurostimulation with other available therapies, the improvements were more substantial than those seen with other available therapies for this patient population, such as motor control exercises. ${ }^{42,43}$ At baseline, average pain was severe (VAS of $7.3 \mathrm{~cm}$ ) and disability marginally severe (ODI of 39.1), but after two years of treatment, average pain and disability were mild ( $2.4 \mathrm{~cm}$ and 17.6 , respectively). Individual clinical benefits were reflected in the "responder" analysis of the core outcome domains, in which $72 \%$ of participants showed a substantial $(\geq 50 \%)$ pain reduction, ${ }^{32}$ with an average improvement from baseline within this cohort of $84 \%$. A total of $67 \%$ of participants reported LBP resolution with an average residual VAS of $0.97 \mathrm{~cm}$, and $61 \%$ of participants reported a substantial ( $\geq 20$ points) ODI improvement, ${ }^{33}$ with an average reduction of 32 points from baseline.

Pain and disability are interdependent symptoms of the underlying etiology and codeterminants of a patient's well-being or health state. ${ }^{44}$ Improvements in each or both of these outcome domains are recognized as treatment success by patients, physicians, and regulators. ${ }^{45-47} \mathrm{~A}$ total of $77 \%$ of participants experienced a substantial improvement in LBP VAS ( $\geq 50 \%)$ and/or ODI ( $\geq 20$ points), and $57 \%$ experienced such substantial improvements in both. The average EQ-5D-5L utility score had increased from 0.585 to 0.798 , which closely approaches the age-matched US population norm of $0.815 .^{48}$

\section{Medication Use}

Insufficient relief from existing treatments commonly leads to prescription of chronic opioid therapy for patients with CLBP, despite frequent poor outcomes. ${ }^{49}$ Even though participants were considered refractory to pain medication, 76 of 204 (37\%) were receiving chronic opioid therapy for their CLBP at baseline. Of the 57 of 156 participants who used opioids at baseline and had a twoyear follow-up, $60 \%$ had either voluntarily discontinued use or decreased consumption, and only one patient had increased intake. These results suggest that the treatment helps patients voluntarily abandon or reduce opioid consumption. Similar reductions were reported for other LBP medications, including nonsteroidal anti-inflammatory drugs (NSAIDs), simple analgesics, and muscle relaxants, providing further support of clinical benefit.

\section{Device Use}

Device use remained high during the second year, with over $94 \%$ of participants delivering treatment. Among the 103 of 155 participants (67\%) with resolution of CLBP, median device use was $48 \%$ (Q1 $15 \%$, Q3 74\%), which was not materially different from the overall distribution. Eight participants did not administer any treatment during the second year, and four of them had resolution of LBP with a residual average VAS of $1.4 \mathrm{~cm}$. A total of 16 participants had administered over $90 \%$ of the maximum permitted treatment amount, and 13 also had resolution of LBP with a residual average VAS of $0.42 \mathrm{~cm}$. This illustrates that even though LBP resolution can be sustained in the absence of stimulation, participants may prefer to continue with therapy delivery despite resolution of their symptoms. Within the remission cohort, three participant profiles are thus emerging: those who stop or minimize stimulation and remain in remission, those who require occasional stimulation to remain in remission or to manage flare-ups, and those who regularly administer a high level of stimulation despite being in remission.

\section{Safety}

The overall incidence of related SAEs was 8 of 204 (3.9\%; Table 3), including six post-surgery infections requiring system removal, all reported during the first four months of follow-up. The permanent system removal rate of 31 of $204(15.2 \%)$ is in line with spinal cord 
Table 2. Outcomes Reported for Completers and All Participants With Stratified Imputation for Missing Data.

Analysis

LBP VAS (cm)

Change in VAS $(\mathrm{cm})$

Change in VAS (\%)

$\geq 30 \%$ improvement in VAS

$\geq 50 \%$ improvement in VAS

$\geq 70 \%$ improvement in VAS

LBP resolution $(\mathrm{VAS} \leq 2.5 \mathrm{~cm})$

ODI

Change in ODI

Change in ODI (\%)

220-point improvement in ODI

Composite of VAS and ODI

$\geq 50 \%$ improvement in VAS and/or $\geq 20$ points ODI

EQ-5D-5L index

Change in EQ-5D-5L index

PPR (\%) $\geq 50 \%$ improvement in VAS and $\geq 20$ points ODI
$6 \mathrm{mo}$

$\begin{array}{lc}\text { Baseline } & \text { Mean }(\mathrm{SE}) \text { or \% }(\mathrm{n} / \mathrm{N}) \\ \text { Mean } \pm \mathrm{SD} & (95 \% \mathrm{Cl})^{*}\end{array}$

Mean \pm SD

$N=190$

$7.3 \pm 0.7$

$3.7(0.2)$

$-3.6(0.2)$

$(-3.9,-3.3)$

$-48.6(2.7)$

$(-53.9,-43.3)$

$66.1(125 / 189)$

$(59.4,72.9)$

$52.9(100 / 189)$

$(45.8,60.0)$

$33.9(64 / 189)$

$(27.1,40.6)$

$39.2(74 / 189)$

$(32.2,46.1)$

$39.1 \pm 10.3$

$21.9(1.1)$

$-17.0(1.1)$

$(-19.2,-14.8)$

$-43.0(2.8)$

$(-48.5,-37.4)$

$48.1(91 / 189)$

$(41.0,55.3)$

$63.5(120 / 189)$

$(56.6,70.4)$

$37.8(71 / 188)$

$(30.8,44.7)$

$0.585 \pm 0.174$

$0.765(0.010)$

$0.180(0.014)$

$(0.153,0.207)$

$55.0(2.5)$

$(50.1,59.9)$

$57.4(109 / 190)$

$(50.3,64.4)$

$64.7(123 / 190)$

$(57.9,71.5)$

$56.8(108 / 190)$

$(49.8,63.9)$
$95 \%(C) *$

$N=204$

$3.9(0.2)$

$-3.4(0.2)$

$(-3.8,-3.1)$

$-47.1(2.6)$

$(-52.3,-41.9)$

$63.2(3.5)$

$(56.5,70.0)$

$51.0(3.6)$

$(44.0,58.0)$

$33.2(3.4)$

$(26.5,39.9)$

$38.3(3.5)$

$(31.4,45.1)$

$22.7(1.0)$

$-16.4(1.0)$

$(-18.4,-14.4)$

$-41.5(2.7)$

$(-46.8,-36.1)$

46.7 (3.5)

$(39.8,53.7)$

60.4 (3.5)

$(53.6,67.2)$

$36.8(3.4)$

$(30.0,43.5)$

$0.758(0.011)$

$0.173(0.011)$

$(0.151,0.194)$

$53.3(2.5)$

$(48.4,58.2)$

$55.1(3.5)$

$(48.2,62.0)$

$62.8(3.4)$

$(56.0,69.5)$

$55.0(3.6)$

$(48.0,62.0)$
1 y

Mean (SE) or \% (n/N)

$(95 \% \mathrm{Cl})^{*}$
$2 y$

Mean (SE) or \% (n/N)

$(95 \% \mathrm{Cl})^{*}$

\begin{tabular}{|c|c|c|c|}
\hline$N=176$ & $N=204$ & $N=156$ & $N=204$ \\
\hline $3.0(0.2)$ & $3.4(0.2)$ & $2.4(0.2)$ & $3.1(0.2)$ \\
\hline$-4.3(0.2)$ & $-3.9(0.2)$ & $-4.8(0.2)$ & $-4.2(0.2)$ \\
\hline$(-4.7,-3.9)$ & $(-4.3,-3.6)$ & $(-5.2,-4.5)$ & $(-4.6,-3.8)$ \\
\hline$-58.9(2.6)$ & $-54.3(2.7)$ & $-66.7(2.6)$ & $-58.1(2.7)$ \\
\hline$(-64.1,-53.6)$ & $(-59.5,-49.0)$ & $(-71.7,-61.6)$ & $(-63.4,-52.8$ \\
\hline $73.9(130 / 176)$ & $66.9(3.4)$ & $82.6(128 / 155)$ & $71.6(3.3)$ \\
\hline$(67.4,80.4)$ & $(60.3,73.6)$ & $(76.6,88.6)$ & $(65.1,78.1)$ \\
\hline $63.6(112 / 176)$ & $58.0(3.5)$ & $71.6(111 / 155)$ & $62.1(3.5)$ \\
\hline$(56.5,70.7)$ & $(51.1,65.0)$ & $(64.5,78.7)$ & $(55.1,69.0)$ \\
\hline $46.6(82 / 176)$ & $43.0(3.6)$ & $61.9(96 / 155)$ & $54.3(3.7)$ \\
\hline$(39.2,54.0)$ & $(36.1,50.0)$ & $(54.3,69.6)$ & $(47.1,61.5)$ \\
\hline $51.7(91 / 176)$ & $47.7(3.5)$ & $66.5(103 / 155)$ & $57.6(3.6)$ \\
\hline$(44.3,59.1)$ & $(40.7,54.6)$ & $(59.0,73.9)$ & $(50.5,64.7)$ \\
\hline $19.0(1.4)$ & $20.7(1.0)$ & $17.6(1.2)$ & $20.2(1.0)$ \\
\hline$-19.9(1.2)$ & $-18.4(1.0)$ & $-21.4(1.3)$ & $-18.9(1.0)$ \\
\hline$(-22.3,-17.6)$ & $(-20.4,-16.4)$ & $(-24.0,-18.7)$ & $(-21.0,-16.8$ \\
\hline $\begin{array}{l}-50.5(2.9) \\
(-563-44.8)\end{array}$ & $\begin{array}{l}-46.4(2.8) \\
(-51.8-41.0)\end{array}$ & $\begin{array}{l}-54.3(3.2) \\
(-60.6,-48.0)\end{array}$ & $\begin{array}{l}-47.5(2.8) \\
(-53.0,-42.0\end{array}$ \\
\hline $57.4(101 / 176)$ & $53.4(3.5)$ & $61.3(95 / 155)$ & $54.8(3.6)$ \\
\hline$(50.1,64.7)$ & $(46.5,60.3)$ & $(53.6,69.0)$ & $(47.7,61.9)$ \\
\hline $73.3(129 / 176)$ & $67.4(3.4)$ & $77.3(119 / 154)$ & $67.4(3.5)$ \\
\hline$(66.8,79.8)$ & $(60.8,74.0)$ & $(70.7,83.9)$ & $(60.4,74.3)$ \\
\hline 47.7 (84/176) & $44.0(3.6)$ & $56.5(87 / 154)$ & $49.9(3.6)$ \\
\hline$(40.3,55.1)$ & $(37.0,51.1)$ & $(48.7,64.3)$ & $(42.8,57.1)$ \\
\hline $0.780(0.012)$ & $0.762(0.011)$ & $0.798(0.013)$ & $0.768(0.011)$ \\
\hline $0.198(0.016)$ & $0.177(0.011)$ & $0.218(0.017)$ & $0.183(0.011)$ \\
\hline$(0.167,0.229)$ & $(0.156,0.199)$ & $(0.184,0.253)$ & $(0.161,0.205$ \\
\hline $65.7(2.4)$ & $60.7(2.5)$ & $72.1(2.4)$ & $62.3(2.5)$ \\
\hline$(60.9,70.5)$ & $(55.8,65.6)$ & $(67.3,77.0)$ & $(57.3,67.3)$ \\
\hline $71.6(126 / 176)$ & $65.9(3.4)$ & $78.6(121 / 154)$ & $68.6(3.4)$ \\
\hline$(64.9,78.3)$ & $(59.3,72.5)$ & $(72.1,85.1)$ & $(61.9,75.2)$ \\
\hline $78.2(136 / 174)$ & 71.8 (3.2) & $80.0(124 / 155)$ & $68.3(3.4)$ \\
\hline$(72.0,84.3)$ & $(65.5,78.1)$ & $(73.7,86.3)$ & $(61.6,75.1)$ \\
\hline $73.3(129 / 176)$ & $67.5(3.4)$ & $77.6(118 / 152)$ & 66.6 (3.6) \\
\hline$(66.8,79.8)$ & $(60.8,74.1)$ & $(71.7,84.3)$ & $(59.6,73.7)$ \\
\hline
\end{tabular}

$3.4(0.2)$

$(-4.3,-3.6)$

$(60.3,73.6)$

$(36.1,50.0)$

$-18.4(1.0)$

(-20.4, -16.4$)$

$-46.4(28)$

$53.4(3.5)$

$(46.5,60.3)$

CGI "Much better"

$\%(\mathrm{n} / \mathrm{N})$ for binary outcomes and $\mathrm{N}$, mean (standard error) for continuous outcomes.

*For continuous outcomes $p<0.0001$ for two-sided $t$-test if change from baseline differs from 0 . 


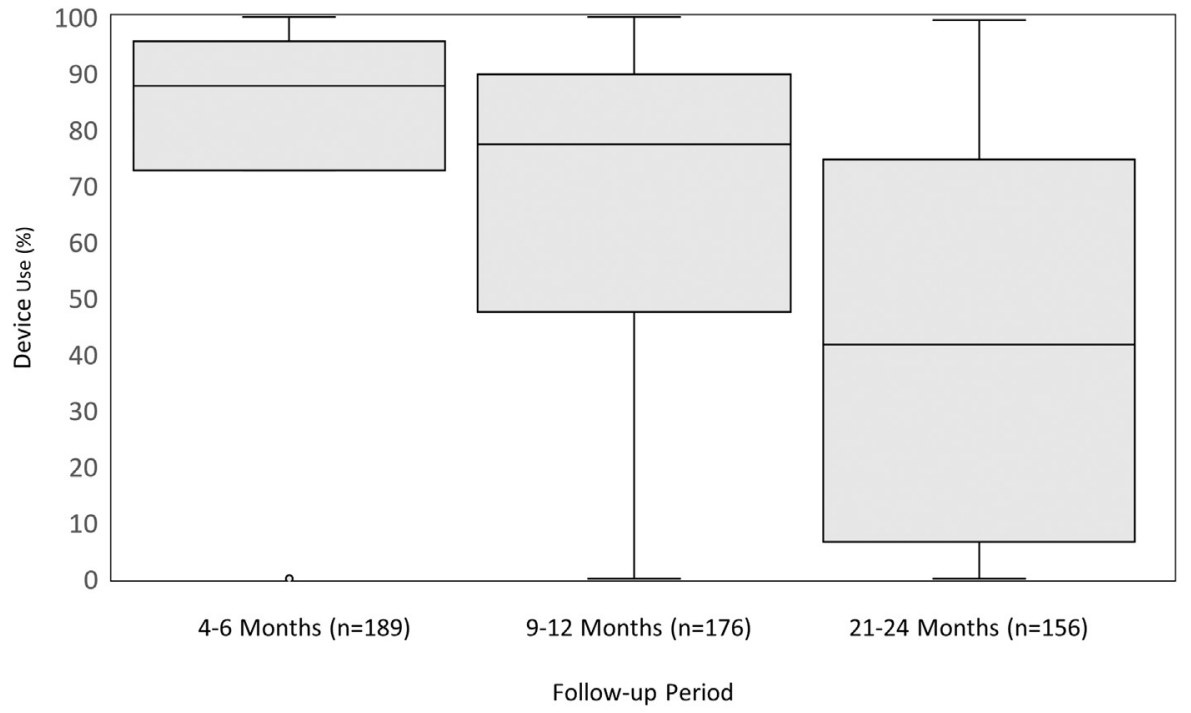

Figure 5. Interquartile ranges of device use as a percentage of the maximum cumulative duration permitted.

stimulation reports over the same two-year period, ${ }^{50,51}$ and the rate of participants requiring surgical intervention, 45 of $204(20 \%)$, is comparable with published incidence data for other neuromodulation therapies for chronic pain. ${ }^{52-54}$ Lead migration represents the most common $\mathrm{AE}$ reported in neurostimulation trials, occurring at the rates of $1.4 \%$ to $13.6 \% .^{52,55}$ No lead migrations were observed in this trial, demonstrating the effectiveness of the distal fixation tines.

\section{Strengths and Limitations}

The strength of this study is that it reports on a relatively large and homogeneous cohort of patients with severe and refractory CLBP with an extended follow-up duration of two years. The study demonstrates durable benefits in patients with a baseline pain duration longer than one year. However, because only three patients had a pain duration between 6 and 12 months, the benefits of earlier intervention remain to be studied.

The main limitation is the absence of a long-term comparator because of therapy activation in the sham-control group after conclusion of the blinded phase at four months. Furthermore, studies with long follow-up durations will inherently have to account for missing data, particularly those for chronic pain conditions. ${ }^{56}$ Indiscriminate use of last observation carried forward has been criticized as a source of systematic bias in chronic pain trials, ${ }^{57}$ and more appropriate methods have been recommended. ${ }^{58-60}$ To inform the interpretation of the complete-cases analyses $(n=156)$, we have provided supporting ITT analyses $(N=204)$ using transparent and conservative MMRM imputation, which was stratified based on likely randomness of, and reason for, missing data. The relatively small difference across all outcome measures between

Table 3. Device- and Procedure-Related SAEs and Surgical Interventions.

Type of event and reason

Events
$n$

\section{Device- and procedure-related SAEs}

Infection (resolved)

Intraprocedural upper airway obstruction (resolved)

Nonradicular patch of numbness on thigh (ongoing)

\section{Surgical interventions and reasons*}

System removal

Reported lack of efficacy

Infection

Facilitate MRI

Participant relocation

LBP pain relief

Reimplant post-infection

Revision

Lead replacement

Pulse generator repositioning
0-6 mo

Patients

$\mathrm{n} / \mathrm{N}(\%)$

$6 / 204(2.9)$

$1 / 204(0.5)$

$1 / 204(0.5)$

8/204 (3.9)
$1 / 204(0.5)$
$6 / 204(2.9)$
$1 / 204(0.5)$
-
-
$1 / 204(0.5)$
$5 / 204(2.5)$
$3 / 204(1.5)$
$2 / 204(1.0)$

6-12 mo

Events Patients

$n$

-

11

8

$-$

3

-

$-$

$-$

5

3

2
n/N (\%)

-

$11 / 204(5.4)$
$8 / 204(3.9)$
-
$3 / 204(1.5)$
-
-
-
$5 / 204(2.5)$
$3 / 204(1.5)$
$2 / 204(0.9)$

12-24 mo

Events Patients

$n$

$\mathrm{n} / \mathrm{N}(\%)$

-
-
13/204 (6.4)
$9 / 204(4.4)$
-
$2 / 204(1.0)$
$1 / 204(0.5)$
$1 / 204(0.5)$
5
$5 / 204(2.5)$
$4 / 204(2.0)$
$1 / 204(0.5)$

* Patients may have had more than one procedure; therefore, the total does not equal the sum of the categories.

${ }^{+}$One patient was reimplanted after the infection cleared. 
the completed-cases and imputed analyses and the statistical significance and clinical relevance of results in both (Table 2 ) instills confidence in the robustness of our data and the validity of the conclusions drawn.

\section{CONCLUSIONS}

The two-year results of the ReActiv8-B trial show durable, statistically significant, and clinically substantial benefits in a cohort of patients with severe, disabling CLBP and multifidus muscle dysfunction who were refractory to conservative care including physical therapy and medications. Participants demonstrated improvements in pain and disability that increased the longer they were treated. This recovery trajectory is consistent with restoration of neuromuscular control and structural muscle changes. The safety profile of the therapy was favorable compared with that of available implantable neurostimulators for the treatment of back pain.

\section{Acknowledgements}

The authors thank the subinvestigators, research coordinators, and nursing staff at the study sites for their contribution to site management and patient care. The authors thank Robert $\mathrm{H}$. Dworkin, $\mathrm{PhD}$, for his advice on interpretation and presentation of trial results, Teresa Yurik, MS, and Lisa Grant, MS, for their statistical advice and data analysis support, and Diane Burnside, BS, and Jason Shiroff, BS (Mainstay Medical Clinical Department), for management of the trial.

\section{Authorship Statements}

Christopher Gilligan, Richard Rauck, James Rathmell, Timothy Deer, Shivanand Lad, Jeffrey Fischgrund, Bruce Mitchell, Kristiaan Deckers, Kris De Smedt, Sam Eldabe, Marc Russo, Jean-Pierre Van Buyten, Ganesan Baranidharan, and Vivek Mehta contributed to the development of the protocol. Christopher Gilligan drafted the manuscript, and Sam Eldabe revised the manuscript. All authors reviewed and approved the manuscript before initial submission. All authors were clinical investigators on the trial, with the following exceptions: Richard Rauck served as chair of the Data Monitoring Committee, James Rathmell served as chair of the Clinical Events Committee, William Klemme served as independent MRI reviewer, and Jan Pieter Heemels provided editorial support.

\section{How to Cite This Article:}

Gilligan C., Volschenk W., Russo M., Green M., Gilmore C., Mehta V., Deckers K., De Smedt K., Latif U., Georgius P., Gentile J., Mitchell B., Langhorst M., Huygen F., Baranidharan G., Patel $V_{\text {., }}$ Mironer E., Ross E., Carayannopoulos A., Hayek S., Gulve A., Van Buyten J.-P., Tohmeh A., Fischgrund J., Lad S., Ahadian F., Deer T., Klemme W., Rauck R., Rathmell J., Maislin G., Heemels J.P., Eldabe S., On Behalf of the ReActiv8-B Investigators. 2023. Long-Term Outcomes of Restorative Neurostimulation in Patients With Refractory Chronic Low Back Pain Secondary to Multifidus Dysfunction: Two-Year Results of the ReActiv8-B Pivotal Trial.

Neuromodulation 2023; 26: 87-97.

\section{SUPPLEMENTARY DATA}

To access the supplementary material accompanying this article, visit the online version of Neuromodulation: Technology at the Neural Interface at www.neuromodulationjournal.org and at https:// doi.org/10.1016/j.neurom.2021.10.011.

\section{REFERENCES}

1. Itz CJ, Geurts JW, van Kleef M, Nelemans P. Clinical course of non-specific low back pain: a systematic review of prospective cohort studies set in primary care. Eur $J$ Pain. 2013;17:5-15. https://doi.org/10.1002/j.1532-2149.2012.00170.x

2. Breivik H, Collett B, Ventafridda V, Cohen R, Gallacher D. Survey of chronic pain in Europe: prevalence, impact on daily life, and treatment. Eur J Pain. 2006;10:287333. https://doi.org/10.1016/j.ejpain.2005.06.009.

3. Alsaadi SM, McAuley JH, Hush JM, Maher CG. Prevalence of sleep disturbance in patients with low back pain. Eur Spine J. 2011;20:737-743. https://doi.org/10.1007/ s00586-010-1661-x.

4. Deyo RA, Weinstein JN. Low back pain. N Engl J Med. 2001;344:363-370. https://doi. org/10.1056/NEJM200102013440508.

5. Förster M, Mahn F, Gockel U, et al. Axial low back pain: one painful area-many perceptions and mechanisms. PLoS One. 2013;8:e68273. https://doi.org/10.1371/ journal.pone.0068273.

6. Saito T, Steinke H, Miyaki T, et al. Analysis of the posterior ramus of the lumbar spinal nerve: the structure of the posterior ramus of the spinal nerve. Anesthesiology. 2013;118:88-94. https://doi.org/10.1097/ALN.0b013e318272f40a.

7. Bogduk N. On the definitions and physiology of back pain, referred pain, and radicular pain. Pain. 2009;147:17-19.

8. Ward SR, Eng CM, Gottschalk LJ, Kim CW, Garfin SR, Lieber RL. The architectural design of the lumbar multifidus muscle supports its role as stabilizer. J Biomech. 2006;39:S101.

9. Kim CW, Gottschalk LJ, Eng C, Ward SR, Lieber RL. The multifidus muscle is the strongest stabilizer of the lumbar spine. Spine J. 2007;7:76S. https://doi.org/10 1016/j.spinee.2007.07.188.

10. Rosatelli AL, Ravichandiran K, Agur AM. Three-dimensional study of the musculotendinous architecture of lumbar multifidus and its functional implications. Clin Anat. 2008;21:539-546. https://doi.org/10.1002/ca.20659.

11. Teichtahl AJ, Urquhart DM, Wang $\mathrm{Y}$, et al. Fat infiltration of paraspinal muscles is associated with low back pain, disability, and structural abnormalities in community-based adults. Spine J. 2015;15:1593-1601. https://doi.org/10.1016/j. spinee.2015.03.039.

12. Freeman MD, Woodham MA, Woodham AW. The role of the lumbar multifidus in chronic low back pain: a review. PM R. 2010;2:142-167. https://doi.org/10.1016/j. pmrj.2009.11.006.

13. Shahidi B, Hubbard JC, Gibbons MC, et al. Lumbar multifidus muscle degenerates in individuals with chronic degenerative lumbar spine pathology. J Orthop Res. 2017;35:2700-2706. https://doi.org/10.1002/jor.23597.

14. Meier ML, Vrana A, Schweinhardt P. Low back pain: the potential contribution of supraspinal motor control and proprioception. Neuroscientist. 2019;25:583-596. https://doi.org/10.1177/1073858418809074.

15. Chou R, Deyo R, Friedly J, et al. Nonpharmacologic therapies for low back pain: a systematic review for an American College of Physicians clinical practice guideline. Ann Intern Med. 2017;166:480-492. https://doi.org/10.7326/M16-2458.

16. Skelly AC, Chou R, Dettori JR, et al. Noninvasive Nonpharmacological Treatment for Chronic Pain: A Systematic Review; 2018. https://doi.org/10.23970/AHROEPCCER209.

17. Tsao H, Druitt TR, Schollum TM, Hodges PW. Motor training of the lumbar paraspinal muscles induces immediate changes in motor coordination in patients with recurrent low back pain. J Pain. 2010;11:1120-1128. https://doi.org/10.1016/j.jpain. 2010.02.004.

18. Hodges PW, Danneels L. Changes in structure and function of the back muscles in low back pain: different time points, observations, and mechanisms. J Orthop Sports Phys Ther. 2019:49:464-476. https://doi.org/10.2519/jospt.2019.8827.

19. Russo $M$, Deckers K, Eldabe $S$, et al. Muscle control and non-specific chronic low back pain. Neuromodulation. 2018;21:1-9. https://doi.org/10.1111/ner.12738.

20. Deckers K, De Smedt K, Mitchell B, et al. New therapy for refractory chronic mechanical low back pain-restorative neurostimulation to activate the lumbar multifidus: one year results of a prospective multicenter clinical trial. Neuro modulation. 2018;21:48-55. https://doi.org/10.1111/ner.12741.

21. Gilligan C, Volschenk W, Russo M, et al. An implantable restorative-neurostimulator for refractory mechanical chronic low back pain: a randomized sham-controlled clinical trial. Pain. 2021;162:2486-2498. https://doi.org/10.1097/j.pain. 0000000000002258

22. Hicks GE, Fritz JM, Delitto A, Mishock J. Interrater reliability of clinical examination measures for identification of lumbar segmental instability. Arch Phys Med Rehabil. 2003;84:1858-1864. https://doi.org/10.1016/S0003-9993(03)00365-4.

23. Moher D, Hopewell S, Schulz KF, et al. CONSORT 2010 explanation and elaboration: updated guidelines for reporting parallel group randomised trials. BMJ. 2010;340:c869. https://doi.org/10.1136/bmj.c869. 
24. Price DD, McGrath PA, Rafii A, Buckingham B. The validation of visual analogue scales as ratio scale measures for chronic and experimental pain. Pain. 1983;17:4556. https://doi.org/10.1016/0304-3959(83)90126-4.

25. Fairbank JC, Pynsent PB. The Oswestry disability index. Spine (Phila Pa 1976). 2000;25:2940-2952 [discussion: 2952]. https://doi.org/10.1097/00007632-2 00011150-00017.

26. Herdman M, Gudex C, Lloyd A, et al. Development and preliminary testing of the new five-level version of EQ-5D (EQ-5D-5L). Qual Life Res. 2011;20:1727-1736. https://doi.org/10.1007/s11136-011-9903-x.

27. Hurst $\mathrm{H}$, Bolton J. Assessing the clinical significance of change scores recorded on subjective outcome measures. J Manipulative Physiol Ther. 2004;27:26-35. https:// doi.org/10.1016/j.jmpt.2003.11.003.

28. Guy W. ECDEU assessment manual for psychopharmacology. 1976. http://www. archive.org/details/ecdeuassessmentm1933guyw.

29. Molenberghs G, Verbeke G. Linear Mixed Models for Longitudinal Data. 1st ed. New York: Springer; 2000.

30. Rubin DB. Multiple Imputation for Nonresponse in Surveys. J. Wiley \& Sons, Inc; 2004.

31. Little RJA, Rubin DB. Statistical Analysis with Missing Data. 2nd ed. J. Wiley \& Sons; 2002.

32. Dworkin $\mathrm{RH}$, Turk DC, Wyrwich KW, et al. Interpreting the clinical importance of treatment outcomes in chronic pain clinical trials: IMMPACT recommendations. J Pain. 2008;9:105-121. https://doi.org/10.1016/j.jpain.2007.09.005.

33. Chou R, Loeser JD, Owens DK, et al. Interventional therapies, surgery, and interdisciplinary rehabilitation for low back pain: an evidence-based clinical practice guideline from the American Pain Society. Spine (Phila Pa 1976). 2009;34:10661077. https://doi.org/10.1097/BRS.0b013e3181a1390d.

34. Ostelo RWJG, Deyo RA, Stratford P, et al. Interpreting change scores for pain and functional status in low back pain: towards international consensus regarding minimal important change. Spine (Phila Pa 1976). 2008;33:90-94. https://doi.org/10. 1097/BRS.0b013e31815e3a10.

35. Walters SJ, Brazier JE. Comparison of the minimally important difference for two health state utility measures: EQ-5D and SF-6D. Qual Life Res. 2005;14:1523-1532. https://doi.org/10.1007/s11136-004-7713-0.

36. Kongsted A, Kent P, Axen I, Downie AS, Dunn KM. What have we learned from ten years of trajectory research in low back pain? BMC Musculoskelet Disord. 2016;17:220. https://doi.org/10.1186/s12891-016-1071-2

37. Chen Y, Campbell P, Strauss VY, Foster NE, Jordan KP, Dunn KM. Trajectories and predictors of the long-term course of low back pain: cohort study with 5 -year follow-up. Pain. 2018;159:252-260. https://doi.org/10.1097/j.pain.00000000000 01097.

38. Dunn KM, Campbell P, Jordan KP. Long-term trajectories of back pain: cohort study with 7-year follow-up. BMJ Open. 2013;3:e003838. https://doi.org/10.1136/ bmjopen-2013-003838.

39. Costa Lda C, Maher CG, McAuley JH, et al. Prognosis for patients with chronic low back pain: inception cohort study. BMJ. 2009;339:b3829. https://doi.org/10.1136/ bmj.b3829.

40. Tamcan O, Mannion AF, Eisenring C, Horisberger B, Elfering A, Müller U. The course of chronic and recurrent low back pain in the general population. Pain 2010;150:451-457. https://doi.org/10.1016/j.pain.2010.05.019.

41. Costa LOP, Maher CG, Latimer J, et al. Motor control exercise for chronic low back pain: a randomized placebo-controlled trial. Phys Ther. 2009;89:1275-1286. https:// doi.org/10.2522/ptj.20090218.

42. Saragiotto BT, Maher CG, Yamato TP, et al. Motor control exercise for chronic nonspecific low-back pain. Cochrane Database Syst Rev. 2016:CD012004. https://doi. org/10.1002/14651858.CD012004.

43. Mueller J, Niederer D. Dose-response-relationship of stabilisation exercises in patients with chronic non-specific low back pain: a systematic review with metaregression. Sci Rep. 2020;10:16921. https://doi.org/10.1038/s41598-020-73954-9.

44. Dworkin RH, Turk DC, Farrar JT, et al. Core outcome measures for chronic pain clinical trials: IMMPACT recommendations. Pain. 2005;113:9-19. https://doi.org/10. 1016/j.pain.2004.09.012.

45. Chiarotto A, Boers M, Deyo RA, et al. Core outcome measurement instruments for clinical trials in nonspecific low back pain. Pain. 2018;159:481-495. https://doi.org/ 10.1097/j.pain.0000000000001117.

46. Food and Drug Administration. Guidance for Industry on Patient-Reported Outcome Measures: Use in Medical Product Development to Support Labeling Claims; 2009.

47. Pham T, Van Der Heijde D, Lassere M, et al. Outcome variables for osteoarthritis clinical trials: the OMERACT-OARSI set of responder criteria. J Rheumatol. 2003:30:1648-1654.

48. Jiang R, Janssen MFB, Pickard AS. US population norms for the EQ-5D-5L and comparison of norms from face-to-face and online samples. Qual Life Res. 2021;30:803-816. https://doi.org/10.1007/s11136-020-02650-y.

49. Qaseem A, Wilt TJ, McLean RM, et al. Noninvasive treatments for acute, subacute, and chronic low back pain: a clinical practice guideline from the American College of Physicians. Ann Intern Med. 2017:166:514-530. https://doi.org/10.7326/M16-2367.

50. Wang VC, Bounkousohn V, Fields K, Bernstein C, Paicius RM, Gilligan C. Explantation rates of high frequency spinal cord stimulation in two outpatient clinics. Neuromodulation. 2021;24:507-511. https://doi.org/10.1111/ner.13280.

51. Hagedorn JM, Lam CM, D'Souza RS, et al. Explantation of $10 \mathrm{kHz}$ spinal cord stimulation devices: a retrospective review of 744 patients followed for at least 12 months. Neuromodulation. 2021;24:499-506. https://doi.org/10.1111/ner 13359.

52. Hayek SM, Veizi E, Hanes M. Treatment-limiting complications of percutaneous spinal cord stimulator implants: a review of eight years of experience from an academic center database. Neuromodulation. 2015;18:603-609. https://doi.org/10. $1111 /$ ner.12312.

53. Eldabe S, Buchser E, Duarte RV. Complications of spinal cord stimulation and peripheral nerve stimulation techniques: a review of the literature. Pain Med. 2016;17:325-336. https://doi.org/10.1093/pm/pnv025.

54. Shamji MF, Westwick HJ, Heary RF. Complications related to the use of spinal cord stimulation for managing persistent postoperative neuropathic pain after lumbar spinal surgery. Neurosurg Focus. 2015;39:E15. https://doi.org/10.3171/2015.7. FOCUS15260.

55. Deer TR, Mekhail N, Provenzano D, et al. The appropriate use of neurostimulation of the spinal cord and peripheral nervous system for the treatment of chronic pain and ischemic diseases: the Neuromodulation Appropriateness Consensus Committee. Neuromodulation. 2014;17:515-550 [discussion: 550]. https://doi.org/1 $0.1111 /$ ner.12208.

56. Kim Y. Missing data handling in chronic pain trials. J Biopharm Stat. 2011;21:311325. https://doi.org/10.1080/10543406.2011.550112.

57. Palmer RH. Estimate at your peril: imputation methods for patient withdrawal can bias efficacy outcomes in chronic pain trials using responder analyses. Pain 2012;153:1541. https://doi.org/10.1016/j.pain.2012.04.024.

58. Permutt TJ. E9(R1)Statistical Principles for Clinical Trials: Addendum: Estimands and Sensitivity Analysis in Clinical Trials. Food and Drug Administration, HHS. 2017: 50433-50434.

59. McNicol E, Ferguson $M$, Bungay $K$, et al. Systematic review of research methods and reporting quality of randomized clinical trials of spinal cord stimulation for pain. J Pain. 2021;22:127-142. https://doi.org/10.1016/j.jpain.2020.05.001.

60. Herbert RD, Kasza J, Bø K. Analysis of randomised trials with long-term followup. BMC Med Res Methodol. 2018;18:48. https://doi.org/10.1186/s12874-0180499-5.

\section{COMMENTS}

The authors have reported long-term outcome data from the ReActiv8-B pivotal trial. This is an important piece of literature providing evidence of long-term effectiveness and durability of restorative neurostimulation in patients with mechanical chronic low back pain secondary to multifidus muscle dysfunction.

Girish Vajramani, MCh, DNB Southampton, England, United Kingdom

Multifidus dysfunction plays a pivotal role in chronic low back pain (CLBP). Axial pain is generally difficult to treat with neurostimulation. Furthermore, the rehabilitation that can be carried out with this device opens an important scenario in the treatment of CLBP. The fact that this is not just a symptomatic treatment option is extremely important. The article provides encouraging data regarding quality of life, pain relief, and reduction in opioid intake. I would like to thank the authors for this study that allows us to look forward with confidence in the treatment of patients having CLBP.

Gianni Colini-Baldeschi, MD Rome, Italy

***

This two-year data of the ReActiv8-B trial shows sustained response and long-term benefit to patients receiving multifidus stimulation therapy long term.

Sarah Love-Jones, MBBS, BSC Bristol, England, United Kingdom 